Jurnal Teknik Komputer AMIK BSI

Volume 7, No.2, Juli 2021

P-ISSN 2442-2436, E-ISSN: 2550-0120

Akreditasi Ristekdikti, No: 36/E/KPT/2019 (Sinta 4)

DOI: $10.31294 /$ jtk.v4i2

\title{
Sistem Penunjang Keputusan Untuk Penentuan Ketua Ekstrakurikuler Menggunakan Metode Profile Matching
}

\author{
Nazmi Uliah ${ }^{1}$, Bakhtiar Rifai $^{2}$, Sopiyan Dalis ${ }^{3}$ \\ 1,2Universitas Nusa Mandiri \\ 1e-mail: nazmi_uliah@yahoo.com \\ 2*e-mail: bakhtiar.bri@nusamandiri.ac.id \\ ${ }^{3}$ Universitas Bina Sarana Informatika \\ e-mail: sopiyan.spd@bsi.ac.id

\begin{tabular}{ccc}
\hline Diterima & Direvisi & Disetujui \\
$02-06-2021$ & $17-06-2021$ & $28-06-2021$ \\
\hline
\end{tabular}

\begin{abstract}
Abstrak - Peranan Ekstrakulikuler Sekolah (EKSKUL) dalam lingkungan sekolah tingkat SMP, SMA, SMK/ sederajat memiliki fungsi yang penting dalam meningkatkan mutu atau lingkungan sekolah, pemilihan yang tepat dalam menentukan Ketua EKSKUL sangat diperlukan agar mampu mengayomi dan menjadi suri teladan bagi siswa/i dalam lingkungan sekolah. Tidak adanya penerapan tetap tentang kriteria khusus, dan tidak adanya pemahaman pemilih dalam memilih ketua ekskul sesuia dengan kriteria, membuat penelitian ini lebih membantu dalam menerapkan kriteria dengan menggunakan metode profile matching. Diharapkan dapat membantu pihak sekolah yang ada pada MA Tarbiyah Islamiyah dalam memudahkan pemilihan ketua EKSKUL. Kriteria yang telah ditentukan yaitu: Aspek Perilaku, Aspek Tanggung jawab, Aspek Komunikasi. Penilaian dilakukan dengan mengisi angket skala likert oleh para responden, dimana Skala $5=$ Sangat Baik, Skala $4=$ Baik, Skala $3=$ Ragu - Ragu, Skala 2 = Tidak Setuju, Skala $1=$ Sangat Tidak Setuju. Hasil diolah dengan metode profile matching, dan Berdasarkan hasil yang didapat perolehan peringkat teratas adalah Dhiyah Fathiyyah dengan nilai akhir yaitu 4,86. Maka dapat disimpulkan bahwa adanya pengaruh dalam penentuan pemilihan ketua ekskul menggunakan metode profile matching sesuai kriteria yang ada.
\end{abstract}

Kata Kunci: Sistem Penunjang Keputusan, Profile Matching, EKSKUL

Abstract - The role of the School Extracurricular (EKSKUL) in a junior high school, high school, vocational high school/equivalent has an important function in improving the quality of school environment, proper selection in determining the Chair of the EKSKUL is very necessary in order to be able to protect and become role models for students in the environment. school. The absence of a fixed application of specific criteria, and the absence of voter understanding in choosing the extracurricular chair according to the criteria, make this study more helpful in applying the criteria using the profile matching method. It is hoped that it can help the existing schools at MA Tarbiyah Islamiyah in facilitating the selection of the chairman of EKSKUL. The criteria that have been determined are Behavioral Aspects, Responsibility Aspects, Communication Aspects. The assessment was carried out by filling out a Likert scale questionnaire by the respondents, where Scale $5=$ Very Good, Scale $4=$ Good, Scale $3=$ Doubtful, Scale $2=$ Disagree, Scale $1=$ Strongly Disagree. The results were processed using the profile matching method, and based on the results obtained, the top-ranking was Dhiyah Fathiyyah with a final score of 4.86. So it can be concluded that there is an influence in determining the selection of extracurricular chairman using the profile matching method according to the existing criteria.

Keywords: Decision Support System, Profile Matching, EKSKUL

\section{PENDAHULUAN}

Kesadaran akan pentingnya pendidikan karakter dirasakan di Indonesia (Faradiba \& Royanto, 2018). Pendidikan karakter sangat penting untuk generasi muda Indonesia karena generasi muda ini nantinya akan menjadi tombak pembangunan bangsa (Noor Yanti, Rabiatul Adawiah \& Mangkurat, 2013).
Sekolah mempunyai peranan yang besar dalam perkembangan individu peserta didik di sekolah (Fadhlyda et al., 2016). Salah satu aspek dari proses perkembangan sistematik dari sistem pembangunan nasional adalah bertujuan utama untuk pembentukan karakter bangsa melalui Sumber Daya Manusianya bukan hanya dari sisi pendidikan tapi juga dari moral kepemimpinannya yang harus dikaitkan dengan 
dinamika lingkungan strategis yang dicirikan dengan globalisasi serta fenomena paradoksnya yaitu unify dan tribalisme (F. Kurniawan \& Karyono, 2010).

Pengembangan potensi peserta didik sebagaimana dimaksud dalam tujuan pendidikan nasional dapat diwujudkan melalui kegiatan ekstrakurikuler yang merupakan salah satu kegiatan dalam program kurikuler (Permendikbud, 2014). Pengembangan diri adalah sebuah upaya untuk mengembangkan dan mengekspresikan dirinya sesuai dengan kebutuhan, potensi, minat, dan bakat yang dimilikinya. Semua itu akan terwujud dari diri peserta didik dengan adanya dorongan dari dalam dan dari luar dirinya. Untuk mengekspresikan minat dan bakat peserta didik di sekolah, maka diadakan kegiatan pengembangan diri berupa kegiatan ekstrakurikuler (Meria, 2018). Selain untuk mencapai tujuan tersebut, kegiatan ekstrakurikuler berperan penting dalam pembelajaran di sekolah. Dengan adanya kegiatan ekstrakurikuler diharapkan dapat menghubungkan kebutuhan perkembangan siswa yang berbeda, seperti kemampuan, perbedaan sikap, kreativitas serta bisa mengembangkan nilai-nilai karakter pada siswa seperti sikap disiplin dan bertanggung jawab (Khairunnisa et al., 2018).

Pembinaan yang diberikan terhadap siswa-siswi pada kegiatan ekstrakurikuler dapat dijadikan sebagai sarana dalam menerapkan pendidikan karakter sebagai suatu terobosan pendidikan di tengah melemahnya karakter generasi muda saat ini, begitu juga peran kepemimpinan merupakan salah satu peran yang sangat penting dan dibutuhkan, oleh karena itu potensi kepemimpinan pada siswa merupakan salah satu potensi yang harus dikembangkan oleh sekolah agar dapat menghasilkan output yang siap untuk menjadi pemimpin di masa depan (Reka et al., 2020). Penyelenggaraan penentuan ketua ekstrakurikuler pada Madrasah Aliyah (MA) Tarbiyah Islamiyah masih kurang optimal terutama dalam hal penilaian calon ketua ekstrakurikuler yang tidak obyektif. Maka penilaian yang digunakan haruslah menghasilkan penilaian yang tepat dan akurat.

Penelitian yang dilakukan oleh Ade Nuraini dkk, menggunakan metode Profile Matching dalam penentuan pemilihan ketua osis, dan untuk menentukan bobot nilai kandidat osis yaitu dengan membandingkan antara kompetensi kandidat kedalam kompetensi pemilihan ketua osis sehingga dapat diketahui perbedaan kompetensinya (disebut GAP), semakin kecil GAP maka dihasilkan bobot nilainya semakin besar, yang berarti memiliki peluang besar untuk kandidat osis menempati posisi ketua (Nuraini et al., 2019). Sedangkan dengan menggunakan analisis pemecahan masalah dengan metode Profile Matching ini maka dapat membantu pihak sekolah dan yayasan dalam memilih siswa yang berhak menerima beasiswa pada SMK ADDA'WAH (Junaidi \& Visella, 2017). Begitu juga Sistem pengambilan keputusan dengan Metode Profile Matching dapat menentukan calon tenaga pengajar atau guru quran baru dalam memberikan informasi yang dibutuhkan secara lebih cepat dan akurat, hasil seleksi calon tenaga pengajar atau guru quran yang otomatis tersaji ke sistem dapat mengurangi kesalahan dan redudansi data $(\mathrm{H}$. Kurniawan et al., 2019). Oleh karena itu, Metode Profile Matching dapat direkomendasikan sebagai salah satu alternatif yang dapat membantu dalam pengambilan keputusan. Terutama dalam kegiatan organisasi dan manajemen sumber daya manusia, sumber daya manusia yang baik akan berdampak positif untuk perkembangan dan kemajuan organisasi atau perusahaan (Purwanto, 2008).

Dengan uraian di atas, penulis menerapkan metode Profile Matching melalui kriteria yang ditentukan, diharapkan dapat membantu pihak terkait di MA Tarbiyah Islamiyah dalam pemilihan ketua ekstrakurikuler agar dalam pemilihannya mendapatkan hasil yang lebih obyektif.

\section{METODOLOGI PENELITIAN}

\section{Tahapan Penelitian}

Dalam penyusunan skripsi ada beberapa tahap yang dilakukan oleh penulis untuk mencapai suatu tujuan, adapun tahapan-tahapan tersebut dapat dilihat pada tahapan penelitian sebagai berikut:

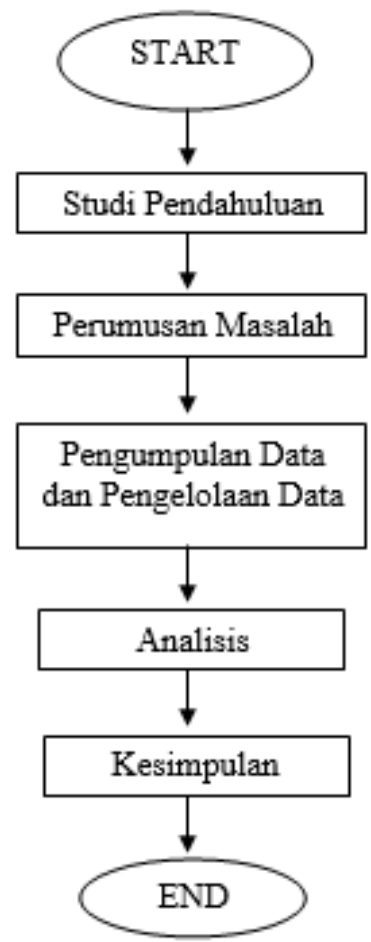

Sumber: (Uliah et al., 2021)

Gambar 1 Flowcart Langkah-langkah Penelitian. 
1. Studi Pendahuluan

Pada tahap ini dilakukan studi literatur dan studi lapangan, studi literatur dilakukan untuk mengkaji dan mengetahui secara teoritis, metode yang dipakai dalam metode pemecahan masalah yaitu menggunakan metode Profile Matching. Sedangkan studi lapangan mempelajari bagaimana menerapkan metode yang sedang digunakan terkait dengan objek penelitian pemilihan ketua Ekstrakurikuler yang diambil pada sekolah Madrasah Aliyah Tarbiyah Islamiyah.

2. Perumusan Masalah

Pada tahap kedua dilakukan perumusan masalah yang terjadi pada objek penelitian sekaligus merumuskan tujuan penelitian. Perumusan masalah didapat dari hasil analisis penelitian pada waktu studi lapangan dan hasil wawancara dengan Kepala Sekolah Bapak Kurnaen S.Pd dan Guru Kesiswaan Ibu Lia Amalia S.Pd selaku guru di sekolah Madrasah Aliyah Tarbiyah Islamiyah. Hasil perumusan masalah ini sekaligus dijadikan tujuan dalam penelitian yang dilakukan.

3. Pengumpulan Data dan Pengelolaan Data Pada tahap selanjutnya dilakukan pengumpulan data-data yang diperlukan sebagai bahan yang digunakan untuk memecahkan masalah yang telah diperoleh pada tahap sebelumnya, yaitu tahap perumusan masalah. Dimana pengumpula data diperoleh dari hasil melakukan wawancara dengan Kepala Sekolah Bapak kurnaen S.Pd dan Guru Kesiswaan Ibu Lia Amalia S.Pd untuk mengajukan beberapa pertanyaan yang berkaitan dengan kegiatan Ekstrakurikuler, serta apa saja kriteria-kriteria yang akan mempegaruhi dalam menentukan ketua Ekstrakurikuler. Kemudian meminta data-data Kegiatan Ekstrakurikuler yang diperlukan untuk kebutuhan analisa lainnya yang di wakili oleh Pembina Kegiatan Ekstrakurikuler. Data-data yang telah diperoleh akan dijadikan bahan untuk membuat kuesioner yang akan diajukan kepada perwakilan anggota, sesuai kebutuhan yang akan diisi. Setelah terkumpul dilakukan pengolahan data yang akan digunakan pada tahap analisis. Pada proses analisis akan dikaji data-data yang ada menggunakan metode Profile Matching yang telah dipelajari pada tahap awal.

4. Analisa Data

Pada tahap selanjutnya dilakukan serangkaian proses analisa, Setelah mendapatkan data-data kegiatan Ekstrakurikuler dari tahap sebelumnya yaitu tahap pengumpulan data dan pengelolaan data. Penulis juga meminta data-data yang diperlukan melalui analisa. Kuesioner yang telah terisi selanjutnya diberi nilai sesuai ketentuan dan akan diolah menggunakan rumus yang akan digunakan hingga ditemukan hasil dari perhitungannya. Hasil pemecahan masalah ini diharapkan memberikan alternatif perhitungan agar lebih baik dalam pemelihan Ketua Ekstrakurikuler di Sekolah Madrasah Aliyah Tarbiyah Islamiyah.

5. Kesimpulan

Pada tahap ini dilakukan analisa dan peringkasan hasil pembahasan masalah dengan metode profile matching. Kesimpulan ini berupa pernyataan yang diambil dari perhitungan yang dihasilkan dari metode penelitian

\section{Instrumen Penelitian}

Instrumen penelitian dari skripsi ini antara lain:

1. Data kuantitatif

Merupakan data berupa angka yang dihasilkan dari suatu perhitungan atau pengukuran yang berasal dari kuesioner, yang dihasilkan dari perhitungan matematika dan akan diolah dengan suatu perangkat lunak komputer yaitu microsoft excel.

2. Kuesioner

Berisikan point-point yang ada dalam setiap aspek yang telah ditentukan, kemudian akan diberikan kepada anggota untuk mencari hasil dari suatu pernyataan yang telah diberikan, kemudian dilakukan pembahasan dari hasil data kuesioner tentang pemilihan ketua Ekstrakurikuler.

\section{Metode Pengumpulan Data}

Dalam pengumpulan data ini penulis menggunakan empat pokok pengumpulan data, yaitu observasi, wawancara, kuesioner dan studi pustaka.

a. Observasi

Observasi diartikan sebagai teknik pengumpulan data, pengamatan atau pencatatan terkait dengan yang diteliti. Dalam rangka mengamati proses pemilihan ketua Ektrakurikuler yang dilakukan secara berkala pada Sekolah Madrasah Aliyah Tarbiyah Islamiyah.

b. Wawancara

Wawancara yaitu teknik pengumpulan data dengan cara berdialog, yang dilakukan oleh peneliti untuk memperoleh informasi. Peneliti melakukan tanya jawab langsung dengan kepala sekolah Bapak Kurnaen S.Pd dan Guru Kesiswaan Ibu Lia Amalia S.Pd.

c. Kuesioner Pengumpulan data dengan menyebarkan kuesioner kepada responden. Responden adalah pemberi informasi yang diharapkan dapat menjawab pernyataan dengan benar dan lengkap. Dalam pelaksanaan responden dalam pemilihan ketua Ekstrakurikuler. Pengumpulan data tidak lain dari suatu proses pengadaan data untuk keperluan penelitian 
d. Studi Pustaka

Pengumpulan data dengan membaca serta mempelajari dokumen-dokumen, jurnal dan buku-buku yang berhubungan dengan objek penelitian. Guna mendapatkan teori/ konsep yang dapat digunakan sebagai landasan teori dan kerangka pemikiran dalam penelitian, dan untuk mencari metodologi yang sesuai serta mambandingkan antara teori yang ada dengan fakta yang terjadi di lapangan.

\section{Populasi Penelitian}

Dalam penelitian ini populasinya adalah kegiatan Ektrakurikuler pada Sekolah Madrasah Aliyah Tarbiyah Islamiyah yang berdomisili di wilayah batu ceper kelurahan belendung kecamatan benda kota tangerang sebanyak 15 kegiatan.

\section{Sampel Penelitian}

Teknik pengambilan sampel yang digunakan adalah saturation sampling yaitu teknik pengambilan sampel bila semua kegiatan populasi digunakan sebagai sampel, syaratnya populasi tidak banyak, atau penelitian ingin membuat generelasi dengan kesalahan sangat kecil.

\section{Metode Analisa Data}

Pada dasarnya metode analisis data dalam menentukan data penelitian ketua Ektrakurikuler di Sekolah Madrasah Aliyah Tarbiyah Islamiyah memiliki kriteria sebagai berikut:

\begin{tabular}{cl} 
& \multicolumn{1}{c}{ Tabel 1. Kriteria } \\
\hline No & \multicolumn{1}{c}{ Kriteria } \\
\hline $\mathbf{1}$ & Aspek Perilaku \\
$\mathbf{2}$ & Aspek Tanggung Jawab \\
$\mathbf{3}$ & Aspek Komunikasi \\
\hline
\end{tabular}

Sumber: (Uliah et al., 2021)

\section{HASIL DAN PEMBAHASAN}

\section{Hasil Penelitian}

Setelah melakukan penelitian maka hasil yang diperoleh oleh penulis dalam penelitian penentuan ketua ekstrakurikuler pada sekolah Madrasah Aliyah Tarbiyah Islamiyah, maka akan dilakukan pengujian menggunakan metode profile matching. Tahapannya adalah sebagai berikut:

\section{Pendataan Responden}

Dalam penelitian penentuan ketua ekstrakurikuler pada sekolah Madrasah aliyah Tarbiyah Islamiyah penulis menentukan populasinya yang diambil sebanyak 30 anggota ekstrakurikuler sebagai penerapan didalam metode profile matching. Responden yang ikut berperan serta dalam penelitian ini adalah guru pada sekolah Madrasah Aliyah Tarbiyah Islamiyah sebanyak 3 responden. Berikut ini adalah nama calon ketua anggota ekstrakurikuler.
Tabel 2. Nilai Aspek Kriteria

\begin{tabular}{ll}
\hline & 1. Sangat Kurang Baik \\
\cline { 2 - 2 } NILAI KRITERIA & 2. Kurang Baik \\
\cline { 2 - 2 } & 3. Cukup Baik \\
\hline & 4. Baik \\
\hline 5. Sangat Baik \\
\hline
\end{tabular}

Sumber: (Uliah et al., 2021)

Tabel 3. Aspek Kriteria

\begin{tabular}{cll}
\hline No & Aspek & \multicolumn{2}{c}{ Sub Aspek Kriteria } \\
\hline $\mathbf{1}$ & Perilaku & Sopan, Santun dan \\
$\mathbf{2}$ & Tanggung & Menghargai \\
& Jawab & $\begin{array}{l}\text { Kemampuan, Kemauan, } \\
\text { Kesadaran } \\
\end{array}$ \\
$\mathbf{3}$ & Komunikasi & Berwawasan dan Tegas \\
\hline \multicolumn{2}{c}{ Sumber: (Uliah et al., 2021) }
\end{tabular}

Perhitungan Nilai Gap

Rumus perhitungan Nilai Gap:

$$
\text { Gap }=\text { Profile Peserta }- \text { Nilai Target }
$$

\section{Perhitungan Nilai Total}

Dari hasil perhitunngan dari setiap aspek diatas kemudian dihitung nilai total berdasarkan presentasi dari core factor dan secondary factor .

\section{Aspek Perilaku}

Nilai total Aspek Perilaku dapat dihitung dengan rumus :

$$
\mathrm{N}=(60 \% \mathrm{X} \mathrm{NCF})+(40 \% \mathrm{X} \mathrm{NSF})
$$

Tabel 4. Nilai total Aspek Perilaku

\begin{tabular}{llccc}
\hline No & Nama & NCF60 & NSF40 & Hasil \\
\cline { 5 - 5 } & Anggota & \% & \% & $\begin{array}{c}\text { (NCF60\%) + } \\
\text { (NSF40\%) }\end{array}$ \\
\hline $\mathbf{1}$ & Adila A. & 4,25 & 5 & 4,55 \\
$\mathbf{2}$ & Ahmad Z. & 4,25 & 4,5 & 4,35 \\
$\mathbf{3}$ & Angel L. & 4 & 4 & 4 \\
$\mathbf{4}$ & Ayubi & 4,5 & 4 & 4,3 \\
$\mathbf{5}$ & Devi Fitri & 4,25 & 5 & 4,55 \\
$\mathbf{6}$ & Dhea Nur & 4,5 & 5 & 4,7 \\
$\mathbf{7}$ & Dhiya F. & 5 & 5 & 5 \\
$\mathbf{8}$ & Dwi A. & 4,25 & 4,5 & 4,35 \\
$\mathbf{9}$ & Elda F. & 5 & 4,5 & 4,8 \\
$\mathbf{1 0}$ & Erika A. & 4,5 & 4,5 & 4,5 \\
$\mathbf{1 1}$ & Fadli F. & 4,5 & 5 & 4,7 \\
$\mathbf{1 2}$ & Falahul F. & 4,5 & 5 & 4,7 \\
$\mathbf{1 3}$ & Farhan F. & 4,25 & 4 & 4,15 \\
$\mathbf{1 4}$ & Farid M. & 4,5 & 4 & 4,3 \\
$\mathbf{1 5}$ & Fawazul & 4,5 & 4,5 & 4,5 \\
$\mathbf{1 6}$ & Firda A. & 4,5 & 4,5 & 4,5 \\
$\mathbf{1 7}$ & Fitriyani & 4,5 & 5 & 4,7 \\
$\mathbf{1 8}$ & Haki & 4,5 & 5 & 4,7 \\
$\mathbf{1 9}$ & Iqramullah & 4 & 5 & 4,4 \\
$\mathbf{2 0}$ & Ira Aprilia & 4 & 4,5 & 4,2 \\
$\mathbf{2 1}$ & Kiki F. & 5 & 5 & 5 \\
$\mathbf{2 2}$ & Mahesa & 4,5 & 5 & 4,7 \\
$\mathbf{2 3}$ & Mutia S. & 4,5 & 4 & 4,3 \\
$\mathbf{2 4}$ & Nella M. & 4,5 & 4 & 4,3 \\
\hline & & & & \\
\hline
\end{tabular}




\begin{tabular}{llccc}
\hline $\mathbf{2 5}$ & Putra & 4,5 & 5 & 4,7 \\
$\mathbf{2 6}$ & Reza & 4,25 & 5 & 4,55 \\
$\mathbf{2 7}$ & Sabila I. & 4 & 5 & 4,4 \\
$\mathbf{2 8}$ & Septian & 4 & 5 & 4,4 \\
$\mathbf{2 9}$ & Syifa U. & 4 & 4 & 4 \\
$\mathbf{3 0}$ & Titis A. & 4,5 & 5 & 4,7 \\
\hline
\end{tabular}

Sumber: (Uliah et al., 2021)

\section{Aspek Tanggung Jawab}

Nilai total Aspek tanggung Jawab dapat dihitung dengan rumus:

$\mathrm{N}=(60 \% \mathrm{XNCF})+(40 \% \mathrm{XNSF})$

Tabel 5. Nilai Total Aspek Tanggung Jawab

\begin{tabular}{|c|c|c|c|c|}
\hline No & $\begin{array}{c}\text { Nama } \\
\text { Anggota }\end{array}$ & $\begin{array}{l}\text { NCF } \\
60 \%\end{array}$ & $\begin{array}{l}\text { NSF } \\
\mathbf{4 0 \%}\end{array}$ & $\begin{array}{c}\text { Hasil } \\
(\mathrm{NCF} 60 \%)+ \\
(\mathrm{NSF} 40 \%)\end{array}$ \\
\hline 1 & Adila A. & 4,25 & 4,5 & 4,35 \\
\hline 2 & Ahmad Z. & 4,25 & 4,5 & 4,35 \\
\hline 3 & Angel L. & 4 & 4 & 4 \\
\hline 4 & Ayubi & 4,5 & 4 & 4,3 \\
\hline 5 & Devi Fitri & 4,25 & 5 & 4,55 \\
\hline 6 & Dhea Nur & 4,5 & 5 & 4,7 \\
\hline 7 & Dhiya F. & 5 & 5 & 5 \\
\hline 8 & Dwi A. & 4,25 & 4,5 & 4,35 \\
\hline 9 & Elda F. & 5 & 4,5 & 4,8 \\
\hline 10 & Erika A. & 4,5 & 4,5 & 4,5 \\
\hline 11 & Fadli F. & 4,5 & 5 & 4,7 \\
\hline 12 & Falahul F. & 4,5 & 5 & 4,7 \\
\hline 13 & Farhan F. & 4,25 & 4 & 4,15 \\
\hline 14 & Farid M. & 4,5 & 4 & 4,3 \\
\hline 15 & Fawazul & 5 & 4 & 4,6 \\
\hline 16 & Firda A. & 4,5 & 4,5 & 4,5 \\
\hline 17 & Fitriyani & 4,5 & 5 & 4,7 \\
\hline 18 & Haki & 4,5 & 5 & 4,7 \\
\hline 19 & Iqramullah & 4 & 5 & 4,4 \\
\hline 20 & Ira Aprilia & 4 & 4,5 & 4,2 \\
\hline 21 & Kiki F. & 4 & 5 & 4,4 \\
\hline 22 & Mahesa & 4,5 & 5 & 4,7 \\
\hline 23 & Mutia S. & 5 & 4 & 4,6 \\
\hline 24 & Nella M. & 4,5 & 4 & 4,3 \\
\hline 25 & Putra & 4,5 & 5 & 4,7 \\
\hline 26 & Reza & 4,25 & 5 & 4,55 \\
\hline 27 & Sabila I. & 4 & 4,5 & 4,2 \\
\hline 28 & Septian & 4,5 & 5 & 4,7 \\
\hline 29 & Syifa U. & 4 & 4 & 4 \\
\hline 30 & Titis A. & 4.25 & 5 & 4.55 \\
\hline
\end{tabular}

Sumber: (Uliah et al., 2021)

\section{Aspek Komunikasi}

Nilai total Aspek komunikasi dapat dihitung dengan rumus :

$$
\mathrm{N}=(60 \% \mathrm{X} \mathrm{NCF})+(40 \% \mathrm{X} \mathrm{NSF})
$$

Tabel 6. Nilai Total Aspek Komunikasi

\begin{tabular}{|c|c|c|c|c|}
\hline \multirow[t]{2}{*}{ No } & \multirow{2}{*}{$\begin{array}{c}\text { Nama } \\
\text { Anggota }\end{array}$} & \multirow{2}{*}{$\begin{array}{l}\text { NCF } \\
60 \%\end{array}$} & \multirow{2}{*}{$\begin{array}{l}\text { NSF } \\
40 \%\end{array}$} & \multirow{2}{*}{$\begin{array}{c}\text { Hasil } \\
(\mathrm{NCF} 60 \%)+ \\
(\mathrm{NSF} 40 \%)\end{array}$} \\
\hline & & & & \\
\hline 1 & Adila A. & 4 & 4 & 4 \\
\hline 2 & Ahmad Z. & 5 & 5 & 5 \\
\hline 3 & Angel L. & 5 & 4 & 4,6 \\
\hline 4 & Ayubi & 5 & 4 & 4,6 \\
\hline
\end{tabular}

\begin{tabular}{llclc}
\hline $\mathbf{5}$ & Devi Fitri & 4 & 5 & 4,4 \\
$\mathbf{6}$ & Dhea Nur & 4,5 & 3 & 3,9 \\
$\mathbf{7}$ & Dhiya F. & 4,5 & 4 & 4,3 \\
$\mathbf{8}$ & Dwi A. & 5 & 5 & 5 \\
$\mathbf{9}$ & Elda F. & 4,5 & 4 & 4,3 \\
$\mathbf{1 0}$ & Erika A. & 5 & 4 & 4,6 \\
$\mathbf{1 1}$ & Fadli F. & 5 & 4 & 4,6 \\
$\mathbf{1 2}$ & Falahul F. & 5 & 4 & 4,6 \\
$\mathbf{1 3}$ & Farhan F. & 5 & 5 & 5 \\
$\mathbf{1 4}$ & Farid M. & 5 & 4 & 4,6 \\
$\mathbf{1 5}$ & Fawazul & 4 & 4 & 4 \\
$\mathbf{1 6}$ & Firda A. & 5 & 4 & 4,6 \\
$\mathbf{1 7}$ & Fitriyani & 5 & 4 & 4,6 \\
$\mathbf{1 8}$ & Haki & 5 & 4 & 4,6 \\
$\mathbf{1 9}$ & Iqramullah & 4 & 4 & 4 \\
$\mathbf{2 0}$ & Ira Aprilia & 5 & 3 & 4,2 \\
$\mathbf{2 1}$ & Kiki F. & 4,5 & 4 & 4,3 \\
$\mathbf{2 2}$ & Mahesa & 5 & 4 & 4,6 \\
$\mathbf{2 3}$ & Mutia S. & 4,5 & 4 & 4,3 \\
$\mathbf{2 4}$ & Nella M. & 5 & 4 & 4,6 \\
$\mathbf{2 5}$ & Putra & 5 & 5 & 5 \\
$\mathbf{2 6}$ & Reza & 5 & 5 & 5 \\
$\mathbf{2 7}$ & Sabila I. & 5 & 3 & 4,2 \\
$\mathbf{2 8}$ & Septian & 3 & 4 & 3,4 \\
$\mathbf{2 9}$ & Syifa U. & 5 & 3 & 4,2 \\
$\mathbf{3 0}$ & Titis A. & 5 & 5 & 5 \\
\hline Sumb & . $(U 1 i a h$ & $2021)$ & & \\
\hline
\end{tabular}

Sumber: (Uliah et al., 2021)

\section{Perhitungan Nilai Ranking}

Hasil akhir dari proses Profile Matching adalah perangkingan pada Anggota Eksrtakurikuler . Perhitungan tersebut dapat dihitung dengan rumus sebagai berikut :

$$
\text { Ranking }=(60 \% \mathrm{X} \mathrm{AP})+(20 \% \mathrm{X} \mathrm{AT})+(20 \% \mathrm{X} \mathrm{AK})
$$

Tabel 7. Rangking

\begin{tabular}{clcc}
\hline No & \multicolumn{1}{c}{ Nama } & $\begin{array}{c}\text { Skor } \\
\text { Akhir }\end{array}$ & Ranking \\
\hline $\mathbf{1}$ & Dhiya Fathiyyah & 4,86 & 1 \\
$\mathbf{2}$ & Putra & 4,76 & 2 \\
$\mathbf{3}$ & Kiki Fernando & 4,74 & 3
\end{tabular}

Sumber: (Uliah et al., 2021)

\section{KESIMPULAN}

Berdasarkan hasil penelitian yang dilaksanakan maka diambil kesimpulan anggota yang mendapatkan ranking tertinggilah yang dipilih untuk menjadi ketua ekstrakurikuler. Penilaian dilakukan secara objektif yaitu dengan menentukan beberapa aspek yaitu aspek perilaku, aspek tanggung jawab, aspek komunikasi. Untuk penilaian menggunakan metode profil matching dengan memberikan kuisioner kepada guru dan hasil kuisioner akan dihitung, sehingga hasil kuisioner dapat menghasilkan data yang akurat. Adanya pengaruh besar untuk menentukan pemilihan ketua ektrakurikuler terbaik sesuai kriteria pada sekolah Madrasah Aliyah tarbiyah Islamiyah. Anggota yang terpilih dari hasil perhitungan metode 
profile matching adalah Dhiya Fathiyyah, Putra, dan Kiki Fernando.

\section{Saran}

Dari hasil penelitian terhadap Sistem Pendukung Keputusan (SPK) Penentuan Ketua ekstrakurikuler menggunakan metode Profile Matching pada sekolah Madrasah Aliyah Tarbiyah yaitu Sistem Pendukung Keputusan (SPK) Penentuan Ketua ekstrakurikuler pada sekolah Madrasah Aliyah tarbiyah Islamiyah dapat dikembangkan menjadi sistem penunjang keputusan berbasiskan Aplikasi $e$-voting sehingga para pengambil keputusan bisa menghemat waktu.

\section{REFERENSI}

Fadhlyda, R., Erlamsyah, E., \& Daharnis, D. (2016). Pembinaan Kegiatan Ekstrakurikuler di Sekolah Menengah Pertama Negeri Kota Sawahlunto. Konselor, 3(3), 101. https://doi.org/10.24036/02014332991-0-00

Faradiba, A. T., \& Royanto, L. R. M. (2018). Karakter Disiplin , Penghargaan , dan Tanggung Jawab dalam Kegiatan Ekstrakurikuler. Jurnal Sains Psikologi, 7(1), 93-98.

Junaidi, A., \& Visella, F. (2017). Pemilihan Penerima Beasiswa Menggunakan Metode Profile Matching. Paradigma, 19(2).

Khairunnisa, Yusuf, N., \& Tursinawati. (2018). Pengelolaan Kegiatan Ekstrakurikuler Di SD Negeri Cot Meuraja Aceh Besar. Jurnal Ilmiah Pendidikan Guru Sekolah Dasar, 3(1), 46-54. http://www.jim.unsyiah.ac.id/pgsd/article/view/ $8636 / 3644$

Kurniawan, F., \& Karyono, T. H. (2010). Ekstra Kurikuler Sebagai Wahana Pembentukan Karakter Siswa di Lingkungan Pendidikan Sekolah. Id. DOAJ. Org (Education Journal), 15, 240-263. http://staff.uny.ac.id/sites/default/files/1323132 81/semornas fik uny (Faidillah 1).pdf

Kurniawan, H., Tanti, L., Fujiati, Agustin, F., \&
Rahmad, I. F. (2019). Decision Support System for Quran Teacher Selection Using Profile Matching Method on TPQ Anbata. Journal of Physics: Conference Series, 1361(1). https://doi.org/10.1088/1742-

6596/1361/1/012011

Meria, A. (2018). Ekstrakurikuler Dalam Mengembangkan Diri Peserta Didik Di Lembaga Pendidikan. Turast: Jurnal Penelitian Dan Pengabdian, 6(2). https://doi.org/10.15548/turast.v6i2.70

Noor Yanti, Rabiatul Adawiah, H. M., \& Mangkurat, P. S. Ppk. F. U. L. (2013). Pelaksanaan Kegiatan Ekstrakurikuler Dalam Rangka Pengembangan Nilai-Nilai Karakter Siswa Untuk Menjadi Warga Negara Yang Baik Di Sma Korpri Banjarmasin. Jurnal Pendidikan Kewarganegaraan:, 36(10), 1573-1576.

Nuraini, A., Hardiyan, \& Rosmiati, M. (2019). Penentuan Ketua OSIS Menggunakan Metode Profile Matching Pada SMK Cengkareng 1 Jakarta Barat. JURNAL BIT (Budi Luhur Information Technology), 16(2), 23-28.

Permendikbud, R. I. (2014). UU RI Nomor 62 Tahun 2014. 53(9), 1689-1699.

Purwanto, H. (2008). Penerapan Metode Profile Matching Dalam Sistem Pendukung Keputusan Penilaian Kinerja Karyawan Pada PT. Hyundai Mobil Indonesia Cabang Kalimalang. Jurnal Techno Nusa Mandiri, XIV(01), 37-40. https://ejournal.nusamandiri.ac.id/index.php/tec hno/article/view/179/156

Reka, W., Burhanuddin, B., \& Sunandar, A. (2020). Pembinaan Potensi Kepemimpinan Siswa Melalui Layanan Ekstrakurikuler. Jurnal Administrasi Dan Manajemen Pendidikan, 3(3), 199-207. https://doi.org/10.17977/um027v3i32020p199

Uliah, N., Rifai, B., \& Dalis, S. (2021). Sistem Penunjang Keputusan Untuk Penentuan Ketua Ekstrakurikuler Menggunakan Metode Profile Matching. 